

\section{A antropologia do consumo}

oje, o consumo de massa dá lugar a padrões de com-
portamento muito mais complexos e segmentados.
Além dos critérios econômicos e regionais, uma gama cada vez maior de aspectos sócio-culturais influenciam o comportamento do mercado, determinando o sucesso ou o fracasso de produtos, marcas e empresas. Nesse cenário, o conhecimento e os métodos de pesquisa da Antropologia Social tornam-se instrumentos valiosos para a gestão de marketing.

por Pedro Jaime Jr. CETEAD / Faculdades Jorge Amado

Fato inegável: a economia segue em processo de reestruturação. Um dos aspectos dessa mudança diz respeito aos padrões de oferta e demanda: o consumo de massa vem sendo substituído por uma nova organização do mercado. Trata-se de uma cultura de consumo marcada pelas diferenças entre diversos estilos de vida, algo que alguns estudiosos chamam de "explosão de micro-identidades": o surgimento e o fortalecimento de grupos sociais que possuem valores, condutas e códigos específicos.

Nesse contexto, as empresas são obrigadas a traçar estratégias alternativas de segmentação de mercado, indo além das classificações tradicionais por região geográfica e renda. A literatura brasileira sobre o mundo dos negócios tem evidenciado essa alteração ao enfatizar, nos últimos 
anos, a presença de aspectos sócio-culturais no comportamento do consumidor. Diversas reportagens de publicações como Exame e Gazeta Mercantil apresentam casos que apontam a necessidade das empresas considerarem a variável cultural na elaboração de suas estratégias de marketing. Vejamos dois exemplos.

A revista Exame publicou há alguns anos uma matéria sobre uma nova linha de produtos da empresa de cosméticos Embeleze, denominada "Beleza Cristã". Voltada para o mercado evangélico, a marca visaria passar uma imagem compatível com os valores adotados por esse segmento da população. A adaptação da estratégia de marketing da empresa ao universo cultural dos consumidores fica clara já nos nomes de seus produtos, como "Colônia Cordeirinho" e "Condicionador Promessa".

A composição do produto não conta com ingredientes de origem animal, como o colágeno, uma vez que, segundo a empresa, os evangélicos não são favoráveis ao sacrifício de animais para fins industriais. Nas embalagens e na publicidade, em vez do tão freqüente apelo sexual, destacam-se versículos bíblicos ("lembra-te de teu criador nos dias de tua mocidade"). A eficácia dessas estratégias pode ser percebida nos resultados financeiros da empresa. Competindo com multinacionais como a Revlon e a L'Oréal, a Embeleze, que também possui produtos voltados para os afro-brasileiros, multiplicou seu faturamento por três durante a segunda metade da década de 1990.

\section{O consumo de massa vem}

\section{sendo substituído por uma nova}

\section{organização do mercado}

\section{marcada pelas diferenças entre}

\section{diversos estilos de vida.}

Uma segunda matéria, também publicada em Exame, intitulada "Prova de obstáculos", trazia a seguinte chamada: "Empresas brasileiras aprendem a competir ao superar hábitos e exigências diferentes no Mercosul". Entre os exemplos citados, o caso da inserção da cerveja Brahma no
Mercado Comum do Sul chamava a atenção.

Pesquisas teriam mostrado que, enquanto o consumidor brasileiro consume mais cerveja na rua, o argentino prefere beber em casa. Assim sendo, a companhia investiu US\$ 150 milhões para fornecer seu produto em garrafas maiores, de 1 litro, naquele mercado. A matéria informava também que, somente na Argentina, a Brahma comercializa um refrigerante à base de pomelo, fruta parecida com a laranja.

À medida que as dimensões sócio-culturais foram ganhando importância crescente na explicação do comportamento do consumidor - como bem ilustram os exemplos acima -, os departamentos de marketing das empresas, os institutos de pesquisa de mercado e as agências de publicidade passaram a recorrer à Antropologia, inclusive recrutando especialistas da área.

A Antropologia e seu método. Consolidada como disciplina científica em meados do século XIX, no contexto do colonialismo, a Antropologia pode ser definida como "o estudo do outro", podendo ser esse "outro" uma sociedade, uma cultura ou um grupo social. A Antropologia busca compreender como a espécie humana, que possui grande uniformidade biológica, apresenta tamanha diversidade de comportamentos.

Para tentar dar respostas a essa questão, a Antropologia, como as demais disciplinas científicas, desenvolveu um método, chamado de etnografia, que significa "descrição de uma cultura”. Até o final do século XIX, os trabalhos de investigação eram realizados pelo que se convencionou chamar de "antropólogos de gabinete", que não tinham contato direto com os grupos sociais estudados. Para construir uma explicação sobre os "estranhos" comportamentos dos povos tribais, eles utilizavam informações passadas por viajantes, missionários e funcionários do governo colonial.

Essa situação modificou-se no início do século XX, e costuma-se atribuir à Bronislaw Malinowski, um polonês naturalizado britânico, os créditos pelo surgimento do método etnográfico, que fundamentou a moderna Antropologia Social. Malinowski defendia que o próprio antropólogo tinha de ir a campo. Principalmente porque seria indispensável ver o objeto de estudo com "olhar antropológico", aquele supostamente desprovido de preconceito, capaz de entender uma cultura diferente a partir das 
razões às quais seus próprios membros recorrem para justificar seus comportamentos.

A partir de Malinowski, o antropólogo passou a ter a obrigação de libertar-se do "etnocentrismo" - a tendência que todos temos de interpretar o outro com base em nossos próprios valores e crenças - e "relativizar" os diferentes costumes e visões de mundo, respeitando as características de cada contexto cultural específico. Para tanto, o pesquisador precisa de uma longa e profunda convivência com o grupo social que deseja compreender.

Originariamente, o objeto do estudo antropológico eram as sociedades tribais. Mas, ao longo do século XX, o campo de atuação foi sendo ampliado. Como já afirmava o antropólogo francês Claude Lévi-Strauss, nos anos 1960, enquanto as maneiras

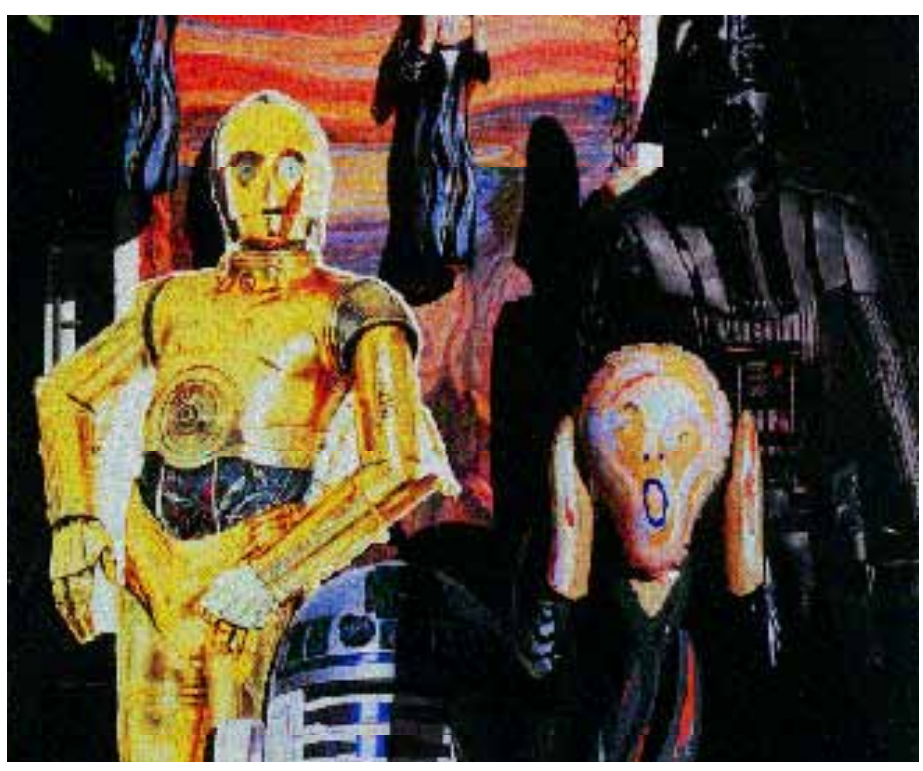
de ser e de agir de certos homens forem problemas para outros homens, haverá lugar para uma reflexão sobre essas diferenças e, portanto, para a Antropologia. Assim, dentro do vasto espectro do que se convencionou chamar de "antropologia das sociedades complexas", muitos novos temas foram se incorporando à disciplina, entre eles, a antropologia do consumo.

Uma nova perspectiva. A antropologia do consumo procura compreender essa esfera da atividade humana com base não apenas nas variáveis de natureza econômica, mas, sobretudo, a partir de elementos e relações sócio-culturais. O antropólogo norte-americano Marshall Sahlins oferece bons exemplos dessa maneira de interpretar o consumo.

Não há nada no plano econômico ou nutricional que impeça a decisão de apresentar a carne de cavalo ou de cachorro como apropriadas para o consumo humano nos Estados Unidos, assegura Sahlins. A escolha alimentar norteamericana, diz o antropólogo, não está baseada em um critério econômico, mas sim em uma definição sócio-cultural.

A classificação dos alimentos como próprios ou impróprios depende da participação do animal como sujeito ou objeto no convívio com os seres humanos. Sendo assim, o cachorro, que possui um nome, veste roupas, senta à mesa com a família, dorme na cama com seu dono, "naturalmente" - ou melhor, "sócio-culturalmente" -, não poderia ser considerado um alimento permitido.

Se o papel do antropólogo é descobrir as lógicas culturais ocultas na sociedade para explicar os comportamentos aparentemente estranhos de seus membros, então pode-se estabelecer uma analogia entre o trabalho desse profissional e aquele desempenhado pelos pesquisadores de mercado e agentes publicitários. Esses últimos procuram responder às constantes reformulações das relações sócio-culturais dentro da vida social, a fim de tornar um "produtosímbolo" um sucesso comercial.

A teoria em ação. Evidenciada a aplicabilidade do conhecimento antropológico para a compreensão do consumo, cabe perguntar se essa perspectiva vem sendo efetivamente mais utilizada e se tem sido bem sucedida na gestão de marketing. A literatura de difusão ajuda a esclarecer essa questão, mostrando como muitas empresas têm obtido resultados concretos.

Outro artigo da revista Exame, sobre a utilização do método etnográfico por algumas empresas, com o título "Tire o traseiro da cadeira", traz dois exemplos ilustrativos.

$\mathrm{Na}$ Gatorade do Brasil, os funcionários foram estimulados a visitar academias de ginástica para observar e conversar com os consumidores. Durante uma dessas visitas de campo, surgiu uma idéia inovadora, ainda que pareça demasiado óbvia. Descobriu-se que os consumidores só tomavam a bebida depois que retornavam para casa, uma vez que não a levavam para a academia com 


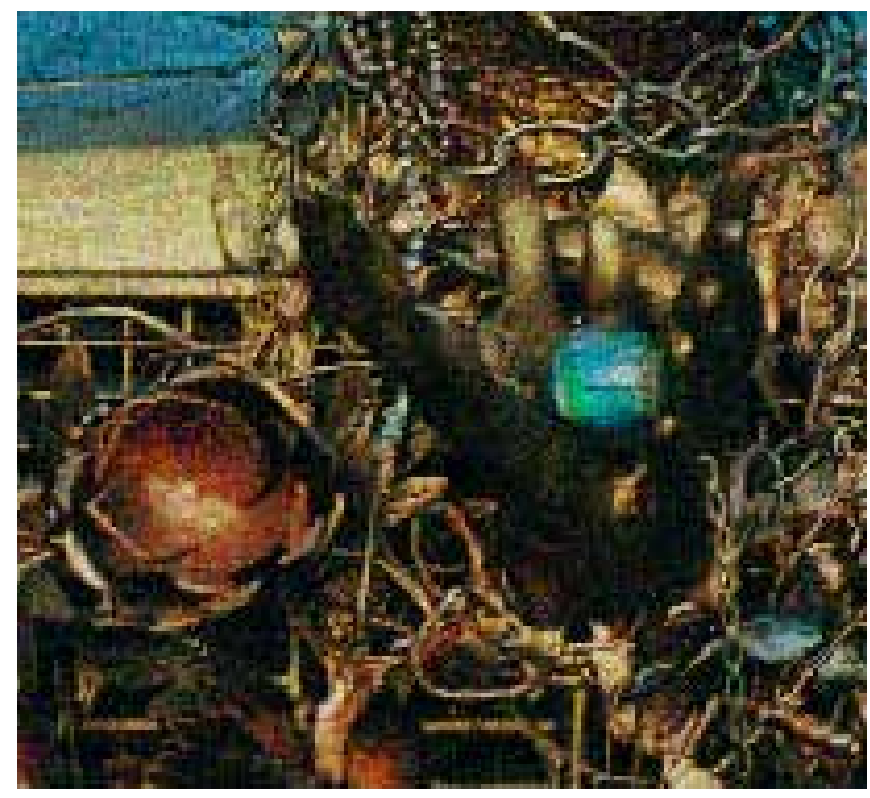

medo que a garrafa de vidro se quebrasse, nem consumiam na cantina por causa do preço elevado. Essa informação, obtida no trabalho de campo, foi a gênese do lançamento do Gatorade em garrafa plástica.

Já a Black \& Decker passava por maus momentos no segmento "faça você mesmo", perdendo espaço no mercado para concorrentes como a Sears. A empresa decidiu, então, estudar em profundidade os hábitos de 50 consumidores, com o propósito de desvendar por que eles preferiam algumas ferramentas em detrimento de outras. Com isso, descobriu que seus clientes queriam potentes furadeiras sem fio e serras circulares que não levantassem poeira. A Black \& Decker redesenhou sua linha de produtos e, como resultado, retomou a liderança do mercado.

De todos os exemplos encontrados na literatura de difusão, um chama a atenção. Trata-se de um programa adotado na Unilever. A empresa transformou seus gerentes em aprendizes de antropólogos. Equipados com gravadores, eles receberam a tarefa de viajar pelo Brasil, subindo morros para entrevistar e conhecer como vivem os consumidores de baixa renda.

O programa fazia parte da estratégia empresarial de desenvolver o mercado de produtos para essa faixa da população. Como o público-alvo da Unilever sempre foi a classe média, aquele era um universo sobre o qual ela possuía poucas informações.
O valor que vem sendo atribuído ao saber antropológico no âmbito da administração mercadológica tem levado alguns profissionais da área a construírem ou reconstruírem seus projetos profissionais, aproveitando as novas oportunidades. As trajetórias de dois antropólogos no campo do marketing, descritas a seguir, ilustram o fenômeno.

Consultoria em marketing. Gerson Santos (nome fictício), além de ter graduação e mestrado em Comunicação, é mestre e doutor em Antropologia Social. Vem atuando como consultor de empresas na fronteira entre a antropologia do consumo e a gestão de marketing. Segundo Gerson: "A Antropologia pode dar uma contribuição enorme ao que se denomina em marketing de comportamento do consumidor. Ela permite entender mais a fundo por que as pessoas compram, de que forma consomem, e como os grupos classificam-se em relação a outros grupos a partir do uso de determinados objetos".

Gerson vem desenvolvendo trabalhos em três direções. A primeira delas refere-se à orientação para elaboração do planejamento de marketing das empresas e definição de ações estratégicas. As metodologias de elaboração do planejamento empresarial tradicionalmente cruzam uma análise do ambiente externo (ameaças e oportunidades do mercado) com um exame do ambiente interno (os pontos fortes e os pontos fracos da organização). As conclusões resultantes desse cruzamento embasam a definição das ações que serão desenvolvidas na condução dos negócios.

Gerson argumenta que o recurso ao saber antropológico é importante tanto na análise externa quanto na interna. No que tange à análise externa, análises sobre as segmentações, transformações e tendências da cultura brasileira, e a percepção das diferenças culturais em um mundo globalizado podem ajudar a empresa a antecipar-se às ameaças e detectar novas oportunidades ambientais. Quanto ao exame interno, o mapeamento das dimensões culturais da empresa representa uma importante contribuição à análise organizacional.

Outra prática desenvolvida por ele é a "etnografia de grupos de consumidores", que envolve pesquisas qualitativas baseadas na observação direta do comportamento dos sujeitos sociais. Essas pesquisas buscam identificar as moti- 
vações de compra com base nas relações entre três elementos: indivíduo, grupos de referência e produtos.

Gerson já foi contratado por grandes empresas para realizar investigações sobre grupos específicos de consumidores. Sua função foi interpretar os significados que os membros dos grupos estudados atribuem a determinados produtos e a seus concorrentes, e desvendar a forma como esses produtos são utilizados.

Gerson presta, ainda, apoio a empresas na relação com suas agências de publicidade. $O$ trabalho consiste em propor estratégias de posicionamento dos produtos no mercado, em função dos valores e da visão de mundo do público-alvo.

Pesquisa de mercado. Cláudia Souza (nome fictício) concluiu a graduação em Ciências Sociais, tem mestrado em Antropologia Social e pós-graduação em Marketing. Após reunir experiência, atuando em diversas empresas, tanto como realizadora quanto como contratante e usuária de pesquisas de marketing, abriu sua própria empresa de pesquisa mercadológica. "Eu sabia fazer pesquisa, por isso percebia as falhas e omissões dos trabalhos que encomendava. Sentia falta de um aprofundamento maior das análises que eram feitas a partir dos dados levantados. Havia possibilidade de fundamentar de forma mais consistente a observação do comportamento do consumidor. Então achei que esse poderia ser o diferencial de meu produto, de minha pesquisa", conta ela.

Segundo Cláudia, as ferramentas adquiridas no curso de Sociologia, e sobretudo no de Antropologia, são muito valiosas para a realização de pesquisas de marketing. Isso porque a pesquisa de mercado busca descobrir as estruturas de raciocínio que embasam os processos decisórios que levam as pessoas a adotar determinados produtos e rejeitar outros. "Quando estou pesquisando um produto, tenho que entender o comportamento do outro. E, para conseguir isso, nada melhor do que pôr em prática o olhar antropológico", afirma ela.

Caminhos perigosos. Dois antropólogos, duas trajetórias distintas. Entretanto, ambas indicam que os departamentos de marketing das empresas, os institutos de pesquisa de mercado e as agências de publicidade têm recorrido ao aporte antropológico, e revelam algumas das con- tribuições que o saber antropológico pode dar ao avanço da gestão de marketing.

No entanto, devemos fazer algumas indagações a respeito desse recurso à Antropologia. Será que o conhecimento antropológico passará a ser, quando utilizado nessas condições, uma sofisticada arma para a dominação simbólica do consumidor? Ao construírem estratégias de marketing lastreadas em interpretações antropológicas cada vez mais refinadas, não estariam as empresas ludibriando os indivíduos?

Responder a essas questões não é uma tarefa simples. Elas exigem um debate acurado. Portanto, não se pretende discuti-las nem resolvê-las aqui. De toda sorte, se existe o risco do conhecimento antropológico ser apropriado de forma espúria no universo do marketing, e isso parece inegável, é preferível que os antropólogos corram esse risco e entrem nesse complexo jogo de interesses.

Ao lançarem-se no jogo, eles devem adotar uma estra-

A assimilação da antropologia pelo marketing pode levar a caminhos perigosos, com o risco desse campo científico tornar-se uma ferramenta sofisticada de dominação do consumidor.

tégia de dupla entrada. Trata-se de conciliar a inserção de antropólogos em organizações empresariais, institutos de pesquisa de mercado e agências de publicidade com a implantação, no ambiente acadêmico, de uma antropologia do consumo lastreada em uma perspectiva crítica e política. Essa nova disciplina pode prestar uma excelente contribuição à compreensão do fenômeno do consumo a partir de uma de suas facetas, muito debatida, mas ainda pouco estudada, do ponto de vista antropológico: o não-consumo.

No intuito de provocar o leitor, encerra-se este artigo com uma provocação do sociólogo português Boaventura de Sousa Santos: "Pior que reduzir o desejo ao consumo é reduzir o consumo ao desejo do consumo". 